\title{
Sus scrofa domestica
}

National Cancer Institute

\section{Source}

National Cancer Institute. Sus scrofa domestica. NCI Thesaurus. Code C14280.

The domestic pig Sus scrofa domestica. 